\title{
The Role of Project-Based Work in Enhancing Students' Autonomous Learning
}

\author{
Sarah Hebbouch ${ }^{1}$ \\ ${ }^{1} \mathrm{PhD}$ student, The English department, Studies in Language and Society Research Unit, Mohammed V University, Agdal, \\ Rabat, Morocco \\ Correspondence: Sarah Hebbouch, PhD student, The English department, Studies in Language and Society Research Unit, \\ Mohammed V University, Agdal, Rabat, Morocco.
}

Received: January 4, 2018

doi:10.11114/ijsss.v6i3.2910
Accepted: January 26, $2018 \quad$ Available online: February 19, 2018

URL: https://doi.org/10.11114/ijsss.v6i3.2910

\begin{abstract}
This study investigates the overall use of project-based work in enhancing Moroccan high school students' autonomous learning and attenuating their being over-reliant on teachers. It was observed, in two Moroccan high schools, -where the study was carried out-, as is the case in many other English foreign language contexts, that students were generally unable to learn by themselves, and that teachers were the solemn imparters of knowledge and learners were merely passive receivers of that knowledge. The study involved a sample of 30 students from science stream belonging to two adjacent high schools, which are located in a big city in Morocco. In the absence of a standard framework on how to implement project-based work properly, effective ways on how project work can improve independent learning proved useful in this study. In order to collect data for the study, three major instruments were employed, involving students and teachers, namely observation, interviews, and survey questionnaires. The data analysis highlighted the importance of project-based strategy in boosting students' autonomous learning, through analyzing interview excerpts of teachers' and students' experience with the concept The research findings revealed that teachers assigned projects for students but did not identify each student's role within a group, which deepened students' disorientation, and reinforced sheer dependence on the teachers. The interviews showed as well the difficulties teachers encountered when assigning projects. This study is but a roadmap to teachers who are willing to increase students' autonomy and improve the quality of the teaching-learning situation. The study also identifies the role of the teacher and the stages that should be followed to a better achievement of results.
\end{abstract}

Keywords: project work, independent learning, students' dependence, autonomous learning

\section{Introduction}

The language landscape has witnessed language-learning tides which put learners at the centre of the learning process. In the student-centered instruction, the role of the teacher is shrunk to the minimum and more emphasis is put on students' independent learning. If properly implemented, Froyed and Simpson (2010) believe that student-centered instruction can amount to increased motivation for learning and greater retention of knowledge. In the face of this, student-centered instruction is immensely based on independence-oriented learning, a strategy by which students develop a range of skills enabling them to study by themselves. (Gardner, 2006) Independent or autonomous learning is ascribed as well to the ability to control important aspects of students' language learning; these assumptions are less common in traditional learning. (Benson, 2012)

Autonomous learning seems to be an ambiguous term that has several possible meanings. Students' dependent learning alludes to the possibility of having learners doing the same thing, in the same way, and even at the same time, and approximately attaining the same results. Students' dependent learning has usually been roughly controlled by an authority, namely the teacher. The contention that has been developed by educational theorists is that learning a language should be reached without having a teacher "in all instances of learning". (Benson, 2012: 37) Notwithstanding that students' over reliance on teachers for receiving every snippet of information can be a stultifying learning style, a burden for teachers and a hurdle for learners. Teachers can, thus, assign the completion of activities as homework tasks, and can even deploy social networking websites for students' learning. The preponderance of autonomous learning is contingent on teachers' engagement and guidance. More importantly, in order to promote independent learning, 
students should have responsibility for their learning through teachers' scaffolding. (Tomei, 2013: 241). In short, learners develop an awareness of the learning processes, of their learning needs, and take initiatives in "planning and executing learning activities through a strategy of recognizing one's weaknesses and strength". (ibid)

\subsection{Research Background}

In a Moroccan English foreign language class, teachers are faced with a vessilitude of students, each of whom has tendencies towards a different learning type and style. Teachers are then supposed to choose strategies for achieved common goals of education, and assure students' learning with minimal direction. Having overly dependent learners, teachers can attempt a task that minimizes students' needs, promotes their academic and social development, and amounts to autonomous learning. To this end, it is assumed that project work, a practice of what students have learnt, is a significant learning strategy that fulfils this goal.

Project-based work is an instructional model that has gained foothold in academic arena and teaching-learning circles by its forerunner, John Dewey. John Dewey supported the "learning by doing" back to the early 1900s, suggesting a new model that kindles students' interest to investigate problems, and fosters students' curiosity to "raise questions, plan and carry out investigations, make observations, and reflect on what they have discovered". (Hassim, Bendouqi, Fahmi, 2006) In project-based work, the role of the teacher has changed from a mere instructor to a facilitator (Fenstermacher \& Soltis, 2004); and, the student, hence, gets involved in the learning process, which cuts short excessive dependence, fosters cooperative learning skills among learners and self-reliance, and promotes scholastic performance and attitudes towards learning. (Hassim et al., 2006)

In project-based work, it is advisable to encourage group work because it has displayed its efficacy as an alternative to conventional classes. (Mallow, 2001: 105). Furthermore, Hassim et al. (2006) argue that students have to develop some abilities, which are as follows:

- Assume responsibility in their learning;

- Learn the skills for quality work, which should be translated into the end-product of the project. The end product should exhibit the learners' accumulation of some traits as, "clarity, relevance, coherence, and creativity";

- Increase the exposure of learners to "authentic materials would promote their interpretive skills which can be achieved through extensive reading and listening to retain the maximum information.

- The presentational skills are of paramount importance to learners, since their presence would allow learners to present and express their ideas to their schoolmates in a good written and spoken manner (Berger, 2012, cited in Hassim et al., 2)

- Knowledge comes to the surface when learners are required to apply it through "problematising, synthesising and using their creative abilities with the information they collect" (ibid: 2);

- Acquire the significance of time management to meet deadlines;

- Develop collaborative skills among group members;

- Train learners on critical thinking (by reflecting on the project) and easily recognize one's strengths and weaknesses;

- Enjoy the experience.

Notwithstanding that the recourse to projects goes hand in hand with the new technologies and ICT in particular, and can "provide more flexible and effective ways for professional development for teachers" (Jung, 2005: 94). More importantly, ICT does not remedy students' learning deficiencies, but it is an indispensable means for information delivery for students, and a facilitator to the delivery of instruction and the learning process. (ibid) Nowadays' learners are mostly technophile and need only some just-in-time support from their teachers. Additionally, research studies in education have claimed that ICT can work effectively only if coupled "with necessary pedagogical strategies" (Dawes, 2001, cited in C.P. Lim, 2007: 84)

\section{Research Methodology}

\subsection{Statement of the Problem}

For many years, learners' excessive dependence on teachers has been an issue of concern in the teaching-learning process in the absence of standard parameters to measure it. Common occurrences in a Moroccan EFL class were identified such as students were over teacher-reliant and were reluctant to speak in class. Underachiever learners were overshadowed in the presence of the over-achievers who extremely dominated the class. This paper discusses the findings of a study conducted in the fall 2016 with the purpose of investigating the efficacy of project-based strategy, as suggested by the Official Guidelines,-an official document issued by the Ministry of education in Morocco, - in 
promoting autonomous learning. The study gauges the extent to which these steps can help overcome some classroom problems corresponding to language, behaviour, and self-confidence building. The study, therefore, seeks the implementation of this strategy and focuses on overall outcomes regarding whether or not students have developed some autonomous learning skills.

\subsection{Research Questions}

The study, conducted in a Moroccan EFL classroom with a first baccalaureate class, attempts to answer the following questions:

RQ1: How can teachers satisfy their students' language needs without having the learners depend on their teachers' intervention?

RQ2: What procedures can the teacher deploy to succeed in projectbased work in an English as a foreign language class?

RQ3: What is the role of the teacher in a project-based learning?

\subsection{Research Objectives}

This piece of research aims to:

1. Provide procedures for project-based strategy

2. Gauge the effectiveness of project-based work implementation;

3. Create a reference study for teachers on the implementation of project-based work in order to minimize students' total dependence on teachers.

\subsection{Participants}

The interview and questionnaire design of the research was used in the current investigation in two adjacent schools, namely Moulay Ali Chrif High School and Maati Bouabid High School, in the city of Rabat, Morocco. The sample was purposefully selected on the basis of comparison, representative average of students, and also on the basis of distance in order to allow the researcher (also a teacher) to move freely back and forth between the two schools. The total number of participants involved in this study was thirty Moroccan high school students from science stream, including 16 girls and 14 boys who volunteered for the study. All participants belonged to a First Baccalaureate class because it is the only level that was assigned to the teacher at the beginning of the year. The number of students was divided into six groups, for which projects were assigned. Because classroom observations are the pillar of any teacher evaluation, the study, therefore, was carried out in the second semester after having observed, in the first semester, that students were over-teacher reliant, with the hope to make an instructional practice more accessible to teachers. Furthermore, a total of 100 teacher respondents were randomly selected from different schools all over Morocco. The respondents were randomly selected from different schools, and they realized how informative their responses can be to the study. This helped engaging only credible, honest, and sincere respondents.

\section{Tools of the Study}

This study is based on three major instruments of data collection, namely observation, interviews, and survey questionnaires. My contention is that a qualitative approach to action research has benefits as to the richness of the information and a deeper insight into the phenomenon it generates.

\subsection{Observation}

In the first semester, students were assigned projects to carry out for the reason of observing their level and needs. The focus was on students' presentations of end products. It was observed that in the presentation of end products, it was the over achievers who showed mastery of the project, while the rest did not display any interest in the subject matter. This means that underachievers were not only over teacher reliant but they depended as well on their classmates on completing their tasks. Without the teacher's supervision and guidance, it is difficult to identify what students' roles are in a group and whether or not they have learnt something.

\subsection{Interviews}

The observation stage has permitted me to identify students' learning needs, suggest a remedial work and evaluate its effectiveness. A rudimentary interview guide was prepared providing a brief list of memory prompts to be surveyed, which is usually used in interviews. Choosing unstructured interviews was primordial because they aim at discussing a limited number of topics for which attitudes are needed. Based on the data I wanted to collect, the questions were designed. 


\subsubsection{Teachers' Interviews}

As concerns interviews conducted with teachers, the focus was placed on whether the teachers had first knowledge about the viability of the method, and whether or not they were aware of the steps that should be followed. We involved twenty teachers of English in the study from different schools to generate an idea about how far they had gone with the implementation of the project-oriented work, given that all of them were familiarized with the term. The state's Official Guidelines to Teaching English as a Foreign Language function as a roadmap to Moroccan high school teachers. The document is a reference to the skills that should be targeted. The interviews were designed in order to elicit information about the use and applicability of project-based work.

\subsubsection{Students' Interviews}

In order to obtain information from a larger sample of students, there was a need for a practical intervention. I selected six groups of students for the study, each of whom consisted of five mixed-ability students (i.e. average, underachievers, and good students). This sample showed a macro view of the major needs and possible solutions, and determined the extent to which the teacher's intervention should be. Notwithstanding that although the study gave idiosyncratic results owing to its limited number of participants who did not account for all students, it was overarching to determine the pros and cons of using project-based work. Groups of students were selected from two different schools (15 students from each school); first, because they shared the same learning community, that is important to the investigation, and, second, this allowed for a direct interaction with individuals in a group setting. I interviewed the participants in order to obtain rich open-ended qualitative data, and get information about students' attitudes, motivations, and feelings towards projects.

\subsection{Questionnaires}

To address the research questions, this study used an approach comprising a qualitative data collection technique since it was meant to test the viability of this pedagogical tool in Moroccan high schools. With the help of other teachers, we managed to distribute the questionnaire to 100 high school teachers of English in the cities of Rabat and Casablanca. Teachers' questionnaires were designed in English because the research targeted teachers of English, whereas students' questionnaires were designed in Arabic because, first, it is the country's official language and all students learnt it since an early age, and, second; students would express themselves in Arabic much better than they would do in English.

\section{Methods of Data Analysis}

\subsection{Interview and Questionnaire Analysis}

The data were qualitative, and were neither coded, nor tabulated because they would not identify the real lacunas of the targeted population in an EFL class. Rather, the study has sought to interpret meaning from these data. Additionally, the study was based on three major activities: observation, face-to-face interviews, and a qualitative questionnaire. Observation was done at two stages: in the first stage, the researcher carefully observed how students interacted in a class, their learning problems, and their needs. In the second stage, observation was participatory since it was based on a direct interaction with students to obtain more information on the subject. Interviews were designed for both teachers and students with the aim of generating attitudes. It was clearly stated in a plain language, considering ethical guidelines, that the provided information was to be used for research purposes only, and that the contribution would be totally anonymous.

Most of the interviews with teachers highlighted the role of projects in calibrating teamwork and collaboration skills. Interviews with teachers unraveled as well that they have read the Official Guidelines to Teaching of English as a Foreign Language designed by the Moroccan Association of Teachers of English, but the guidelines did not provide practical ways to proceed with project-based work. The document devotes a small section to the introduction of the strategy. However, the lack of instances, samples, and features of how to succeed project-based work contributed to teachers' and students' confusion about the strategy. The Moroccan Ministry of Education along with the Moroccan Association of Teachers of English have both designed the aforementioned guide, and made it available to teachers on the Ministry's website.

As important, the study employed a qualitative mode of questionnaire to guarantee high response rate and chart opinions from both teachers of English and students belonging to other schools. The questionnaire has sought to elicit information; first, from teachers, who are asked by the pedagogical supervisor, at the beginning of each academic year, to supervise students' projects, and give marks for the end-products; and, second, from students in order to generate the shortcomings of the way project-based learning is approached.

\section{Intervention Procedures}

To ensure the viability of the suggested solutions, I selected mixed-ability groups for the study and held a weekly meeting with the groups to derive maximum information from them, and guide them through planning. In order to achieve this, I 
exploited an online platform that I asked students to adhere to it so as to track their progress. To proceed with projects, the focus was placed more on meaning rather than language. The contention was that project-based work should target learners' interests rather than language elements per se, but it also meant that this strategy should help students overcome their language problems. Interestingly enough, the choice of the themes had to be on par with the textbook and the learning context, that is, classroom or community. The students were asked to choose themes related to the textbook, yet the teacher's role was not to influence their choice but to guide them through planning. Nevertheless, the teacher suggested that the choice of the topics demonstrate such attributes as description, comparison of social, environmental, political, and health issues.

The students were given a written form of the guidelines to follow. The guidelines comprised brainstorming on the ideas, identifying the inspiring topic and achieving consensus on it. When finalizing the topic, it should be then broken down into parts, which can be done through encouraging students to investigate other aspects that might determine the final outcome, by selecting the techniques of presenting the end-product. The stages also entailed the outline on how to develop the project and encourage students to look for sources of information through some modes of collection: library research, letters, interviewing, and watching ready-made videos for more inspiration.

To identify skills and strategies, practice in question formation was needed. We held a session specifically with the groups of students to remedy problems related to question formation. With the teacher's guidance and counsel, students learned how to formulate questions through designing interviews, had hands-on the different types of writing tasks because they were required, as part of the formative evaluation, to submit a written summary on the findings and their work. Besides, gathering information was an integral part of the formative evaluation, and helped assess students' wittiness of collecting relevant information, gathering printed and visual material, planning, compiling, and analyzing information, and unnecessary information. In the final summative assessment to the overall results, learners presented the final product, by, first, submitting a final written short report, preparing classroom information (wall displays), and demonstrating their journal to their classmates on who did what. The end-product was not an end to the project, but a practice through which students evaluated the project by reflecting on the experience, knowledge they gained, skills they acquired, difficulties and implications of the project, and alternatives to improve the quality of projects.

\subsection{The Role of the Teacher}

Observing the research situation, I could deduce that the role of the teacher is to diagnose and rectify errors committed throughout the process of projects, and set time limits and deadlines. When students know that their project is going to be presented to the class, this influences the nature of the project from "the moment they start working" on it, because they would take meticulous care of their work, which boosts the incentive of ambition and commitment, and facilitates the supervision tasks for the teacher. The present study has concluded that the teacher's role was to supervise and give feedback on the multiple drafts of the interviews, has identified the relevant issues within the same topic, has assisted in defining the procedures, and has helped organize the project timeline. The teacher's role is to assess improvement and progress, and hold formal critique sessions. Formal critique sessions were usually held through an online platform, Facebook, where all the students had an account, and where all students would reconnect to seek help from their teachers.

The use of ICT in projects results in increasing productivity in the context of technology, it helps expand beyond the linear text-based learning, as this is the mode of learning most commonly proved useful in facilitating the project implementation. In some instances, technology can play a role by contributing to students' interests. It can facilitate the project implementation, and "can contribute to how interesting and valuable students find projects. Students are more likely to take part in project-based learning when projects focus on questions that they perceive as valuable". (Blumenfeld et.al. 1991: 384) The prime purpose is to promote challenge for students to collaborate via social networks and instead of misusing them, the benefit will be higher.

Projects tend to be in core like classes, and a sound understanding of how students deal with projects and their supervisor stipulates the introduction of rules of conduct at the beginning to ensure the fluid continuity of projects, and to manage group work. Designing rules at the beginning tends to nourish an attitude of compliance, respect, and assiduity. The rules prepared for this study are in the form of items to be followed:

- The students exchange views and information among themselves (this would summon cooperation);

- For both teachers and learners, they need to keep track on the activities learners are involved in through scholastic diaries, and see their progress and individual work;

- Teachers and learners should reflect on the learning process, for through reflection, learners make self-assessment; 
- To achieve class unity, students support each other from start to finish; it is advocated that students take the pedagogical lead. In relation to learner autonomy, this role is held by one student and then another one "in a complex structure of interdependence". (Tuloiu and Stefansdottir, 2011:26)

\section{Findings and Discussion}

The study has vehicled a general picture of the persisting problem of the teaching and learning situation in Moroccan high schools. The major finding of this piece of research, after implementing some of the suggested solutions, to help cease the problem that has plighted the Moroccan EFL classroom, namely, the burgeoning phenomenon of students becoming more and more teacher-dependent, tends to fall into many areas. The findings, first and foremost, list the virtues of students working on projects with the intention to develop the ability to develop some language skills by themselves with a minimum support of teachers. Project-based learning encourages the use of meta-cognitive processes, assesses students' progress, diagnoses problems, provides feedback, and evaluates overall results.

The teacher's major role is to guide the students throughout the process of conducting their projects. Interviews have shown some conflicting views related to how to guide students in this respect. In the interviews, most of students claimed that their teachers assigned project work for them and that they did not perform well because they did not know each student's role within a group. One of the students said: "I have always been assigned a project, but mostly it is my classmates who do the job instead of me because I don't know what to do". This explains that tasks were not assigned properly among students and that they lacked orientation. Some respondents asserted they have learnt how to collaborate and enjoyed being in a group, while others declared their dislike to group work because they do not get along with other students. More importantly, interviews showed students' lack of orientation especially when it is group work, since most of them used to work individually on projects. Students purported they were hampered by the school's shortage of equipment that facilitates conducting projects (camera, tripod, computer as such). They complained about the fact that the school's staff had it that it was safer to keep the equipment locked up, and hence, students did not benefit from the high-tech equipment, which determined the overall quality of the end-product. Regarding preferred themes, respondents concluded that the textbooks' themes were more relevant to their learning style. Teachers' attitudes, however, revealed the role of project work in improving students' independent learning.

The researcher sets out a guidance canvas before actually assigning projects to students. The study has shown that guiding students to get the most out of the learning resources should be done by supervising their work meticulously, helping them with sources of information, and encouraging them to use their imagination. Nevertheless, teachers should, at the same time, have an action plan as to keep the group harmony alive. The teacher's role was also to equip students, provide them with the information and support in order to acquire some smattering knowledge about the topic they investigate. Each group worked on a specific theme; for example, they investigated the causes behind students' disinterest in learning and schools. Since the groups consisted of five members, they tried to dismantle the topic into three parts, each of whom was held accountable for one. While mentoring groups, counseling was essential on how to limit the scope of each part, either through explaining, or through giving further information.

Based on the findings of the questionnaire, and according to a high school teacher, "the most essential aspect of project work is not the end-product itself, but the range of skills students develop throughout the work". Eighty-two teachers out of a hundred confirmed that students' teamwork and collaboration skills, as well as communication skills increased and they observed that students communicated with each other without problems. Fifteen teachers out of one hundred claimed they did not assign topics; rather, they made their students decide on the theme they want to investigate, though at times, a respondent said: "they didn't reach consensus and quarreled with other, and I had to interfere and assign a subject for them to work on". Seventy-seven respondents (teachers) were ignorant of the Official Guidelines to TEFL, though the document was available on the Ministry of Education's website and was designed to be within the teachers' easy reach. That said, we can deduce that teachers are only familiar with the project-work strategy, but are not cognizant of its procedures such as the number of students who can be in a group, the time-frame of the tasks, the end-product, and the way the evaluation can be carried out. In what follows, I discuss how I carried out the suggested intervention procedures.

Little has been said about how to evaluate students. The Official Guidelines suggest the evaluation of the final presentation of the project, which immensely subverts students' laborious work. In order to assess students evenly, it is suggested that teachers prepare an evaluation grid as part of the formative and summative assessment. This type of evaluation is more effective to stimulate important instructional decisions based on the processes, students' cooperation, commitment, and punctuality rather than the end-product. Summative assessment should be the last phase in the project, in which teachers can evaluate students' performance and time management of the project.

The formative evaluation of the process was in the form of comments and suggestions for improvements. Moreover, the evaluation was extended to language use as well. Therefore, students were asked to submit a written summary on the 
findings and the progress of their work to measure their linguistic progress, and whether or not they were able to deploy what they have learnt in the classroom such as capitalization, rectifying spelling mistakes, and rectifying French interference and tenses. Proofreading was as well quintessential, especially that students unanimously agreed that their presentation would be in the form of a video. Additionally, because the final product had to be delivered to their classmate, the teacher took meticulous care of correcting students' interview drafts and voice-over. In the same vein, preparing an evaluation grid was primordial to keep the pace with students' progress; the prime purpose of the grid was to put stress on some significant items such as:

- Tasks (carry out tasks appropriately)

- Collaboration (ability to work in groups)

- Punctuality (students' meeting deadlines)

- Creativity

- Performance (time management and good articulation)

- Originality

- Language use

Weekly meetings were important enough to generate an idea about students' tendencies. Students relied heavily on technology, and this, by no means, ensured that they get a good amount of useful and insightful opinions about their work. Hence, creating a page on a social media-networking website was a concrete experience in defining students' needs. The data gathered in this study confirm that even underachievers, very often underestimated, are more inclined to assume responsibility and play roles, which is immensely ascribed to the way the tasks within a group are distributed. The teacher assigned purposefully less demanding tasks to underachievers such as finding relevant pictures for the theme of the project, searching for appropriate music, and participating in editing the final product.

On the overall, students exhibited a good sense of selecting the main information to include in their projects. The teacher had to direct their attention to certain issues, but so much leeway was granted to students in as much as to give them a chance to be creative in the way they like. In the first semester, some students exhibited a disruptive behavior in the classroom, and negatively affected the smoothness of the lesson. Understanding the types of disruptive classroom behavior may help in solving the problem. We started by selecting effective classroom management strategies to eradicate these frequent types of discipline problems. When the teacher engaged the students in the project, disruptive behaviors attenuated. They would raise their hands to read or to write a sentence on the board, minimizing thereby off-tasks. The teacher encouraged students through positive reinforcement, and showed disruptive and underachiever students that they can also "steal the show". (Anonymous, 2012)

The study demonstrates that projects can solve problems like faulty behaviors in language, off-tasks, can engage students of different learning capabilities and language skills, and can be a haven to escape boring material since students find pleasure in breaking the linearity of the lesson. If a teacher allocates sometime at the end of the session to the students to present their projects, this will create a fruitful environment and put an end to the boring materials. On the day of the presentation, groups, who met the deadline, were ready to deliver their presentations. Students were evaluated on their performance and time management. They were permitted time for the presentation in a formal way, were asked questions from their classmates on how they gathered information, and received feedback on it. They came up with a good end-product, with an introduction telling the audience what would happen with a sound argument, a body, and a conclusion, supporting their argument with pertinent evidence.

Delivering the project was a good practice for the speaking activity; first, because it helped students liberate themselves from public speaking complexes, second, it enhanced their self-confidence. The teacher was aware of the students getting up in front of a large audience and speaking, a practice that is more "terrifying than death". (ibid) The groups took turns; each member was in charge of a particular part in the presentation. Grammatical mistakes attenuated thanks to prior correction of mistakes. With projects, faulty language is palliated when students memorize the lines, and, henceforth, memorize irreproachable language.

\section{Limitations}

Although efforts have been invested to make the study as comprehensive as possible, I am still aware of its unavoidable limitations and shortcomings. First of all, because of the time limit, the study was undertaken in ten weeks. Ten weeks is not enough for a researcher to observe the problems, plan a remedial work, implement it, and then evaluate its results. It would have been better if it was conducted in a longer time. Second, the population sample (15 students) was selected from two adjacent schools, which means that the research was conducted on a small size of population; it also cannot be generalized to the larger population students. The study should have involved more students from different levels, and, 
thus, culminate in a representative average. Last but not least, the scant number of references in addition to the absence of concrete samples of how project-based strategy was implemented in Moroccan schools has been a predicament in this study.

\section{Conclusions, Implications, and Recommendations}

This study enabled me: first; to explore the extent to which the Moroccan EFL teachers are acquainted with the content of the Official Guidelines and project-based learning; second, to determine whether or not project work undertaken to enhance students' reliance on teachers, as purveyors of knowledge, is reflective of autonomous learning. The study has enabled me as well to draw valid conclusions, most of which came in confirmation of my initial research statement of problem.

Carrying out project work is acknowledged to be a prerequisite to developing students' self-directed learning. It allows students to enhance their sense of self-responsibility, critical thinking, problem solving, and quality work production. It also reinforces their ability to plan purposefully, collect, process, and evaluate relevant data, develop their own material, and finally present it to an audience in the form of an oral presentation, a written report, a poster, a file, etc. It is noteworthy as well that project work permits teachers to recycle the four skills (reading, writing, listening, and speaking) as students process large amounts of input and attempt to reproduce it in the form of output.

Through project work, students are also given the opportunity to explore real-life issues of their own choice. Project work is an exceedingly motivating experience in the sense that students will partly work outside the classroom, and will "own" the end product, which will be the outcome of a challenging experience. Project work has now become part and parcel of the Moroccan syllabus for EFL teaching. Still, most EFL teachers seldom, if ever, attempt to go beyond the textbook, which is very much detrimental to the potential language skills students will learn as a result of their conducting project work.

The analysis of the findings of the current study has yielded a number of conclusions that are worth mentioning in this section. To begin with, the success of project-oriented work is determined by the teacher's paramount role. The teacher needs to be "clear about [the projects'] aims and objectives, be aware of its wide scope and the numerous benefits learners may gain from, but also the challenges [they] may pose". (Hassim et al, 2006: 45) Furthermore, the suggested stages on how to succeed project-oriented work outline a project of training students to be life-long independent learners. These suggestions sustain the main objectives of the Moroccan National Charter of Education in training learners to become autonomous learners without discarding the teachers' major role in canalizing knowledge, forming classroom discipline plan, and fostering a favorable learning climate through developing positive teacher-student harmony.

Finally, I have a set of recommendations that could be used to inform the future research agenda. It is recommended that further research be undertaken in this area; especially that it places a higher premium on students' development of autonomous learning. It is highly suggested that teachers give formative feedback on process and product, and in this way, students would take their projects seriously. It is also advisable to limit the time allotted for submitting the final product, and to have a hand in determining the number of students who should be in a group.

It is hoped that through such objectives and techniques, my future students will be able not only to learn how to work in a collaborative and interactive environment, but also to transfer the skills they have acquired in their language class to other subjects, and even, at a later stage, to their professional life.

\section{Acknowledgements}

This piece of research could not be possible without the help and emotional support of my mentor, Dr. Jamal Din Slimani. I am grateful to his insight and expertise as regards the research, his encouragement to pursue this topic, and his help to achieve a clearer structure. I am also indebted to Prof. Noureddine Amrous for sharing his pearls of wisdom. I am thankful to all those with whom I have had the pleasure to work during this project, especially students and teachers who volunteered for the study. To all these energies, I express my gratitude.

\section{References}

Anonymous. (2007). Designing Effective Projects: Characteristics of Projects Benefits of Project-Based Learning. Intel (Teaching Program). Retrieved from: http://download.intel.com/education/Common/pk/Resources/DEP/projectdesign/DEP_pbl_research.pdf

Anonymous. (2012). Promoting Learning Autonomy through Multiliteracy Skills Development in Cross-Institutional Exchanges. Journal of Language Learning and Technology, 16(3), 82-102.

Anonymous. (2012). Why is public speaking so scary? Retrieved from http://www.socialconfidencecenter.com/2012/why-is-public-speaking-so-scary/ 
Benson, P. (2012). Autonomy in Language Learning, Learning and Life. Hong Kong Institute of Education. Synergies France $n^{\circ} 9,29-39$. Retrieved from: https://gerflint.fr/Base/France9/benson.pdf

Berger, R. (February 2012). Work that matters the Teachers' Guide to Project-Based Learning. Paul Hamlyn Foundation. Retrieved from: http://www.innovationunit.org/sites/default/files/Teacher's\%20Guide\%20to\%20Project-based\%20Learning.pdf

Blumenfeld, P. et al. (1991). Motivating PBL: Sustaining the Doing, Supporting the Learning. Educational Psychologist, 26(3\&4), 369-398. https://doi.org/10.1080/00461520.1991.9653139

Fenstermacher, G., \& Jonas, S. (2004). Approaches to Teaching. New York \& London: Teachers College Press. $4^{\text {th }}$ Edition

Froyd, J., \& Nancy, S. (2000). Student-Centered Learning Addressing Faculty Questions about Student-Centered Learning. Retrieved September 29, 2014 from: http://ccliconference.org/files/2010/03/Froyd_Stu-CenteredLearning.pdf

Gardner, H. (2006). Multiple Intelligences: New Horizons in Theory and Practice. New York: Basic Books.

Hassim. A. et al. (2006). English Language Teaching Guidelines For Second Year Baccalaureate [Level Four]. Newsletters of the Moroccan Association of Teachers of English, Volume 27 (Issue I).

Jung, I. (2005). ICT-Pedagogy Integration in Teacher Training: Application Cases Worldwide. Journal of Educational Technology \& Society, 8(2), April, 94-101. Retrieved from http://www.jstor.org/stable/jeductechsoci.8.2.94

Mallow, J. V. (2001). Student Group Project Work: A Pioneering Experiment in Interactive Engagement. Journal of Science Education and Technology, 10(2), 105. https://doi.org/10.1023/A:1009468912400

Ping Lim, C. (2007). Effective Integration of ICT in Singapore Schools: Pedagogical and Policy Implications. Educational Technology Research and Development, 55(1), February, 83-116. https://doi.org/10.1007/s11423-006-9025-2

Tomei, A. L. (2013). Learning Tools and Teaching Approaches through ICT Advancements. Pennsylvania: Information Science Reference. https://doi.org/10.4018/978-1-4666-2017-9

Tuloiun, A., \& Ina, S. (2011). Learner Autonomy: Theoretical \& Practical Information for Language Teachers. Retrieved from: http://skemman.is/stream/get/1946/7668/19634/1/ 


\section{Appendix}

The questionnaire administered is as follows:

\section{Teachers' attitudes}

This questionnaire aims at investigating teachers' attitudes toward the role of project work in enhancing autonomous learning. All the information provided by the teachers will be used for research purposes only.

Please answer the questions carefully. Your contribution will be totally confidential. Thank you beforehand for your contribution and for the time you will devote to answering these questions.

The English Language Teaching Guidelines for Second Year Baccalaureate define "project" as "an activity in which learners, as individuals or groups, gather data from a variety of sources, process it in order to achieve a pre-stated objective and finally present it to the whole class".

MATE Newsletter, Summer 2006, Volume 27 (Issue 1) p. 43

\section{Very important: Do not write your name.}

Please put a Tick $\sqrt{ }$ in front of your answer.

Please answer the following questions:

\section{Do students like working on project work?}

Yes [ ]

2. Do students show progress when they do project work?

Yes [ ] No [ ]

3. What are the skills that you think students will develop when doing project work?

- Critical thinking and problem-solving [ ]

- Teamwork \& collaboration skills [ ]

- Effective communication skills [ ]

- Assessing and analyzing information

- Curiosity and imagination

Others.

4. Do students like doing projects on their own? Or do they like collaborating? Justify your answer.

5. Does the curriculum allow for the use of project work?

Yes [ ]

No [ ]

6. Do you assign topics for students?

Yes [ ]

No

7. If yes, what kind of topics you encourage your students to work on?

Topics related to the curricula

Real-life issues

Topics of concern to the students

Others 
8. How many students do you think should be included in a project?

9. What kind of guidance should a teacher give his/her students?

10. How much time do your students need to complete a project?

11. Which form of the end-product do your students prefer to use?

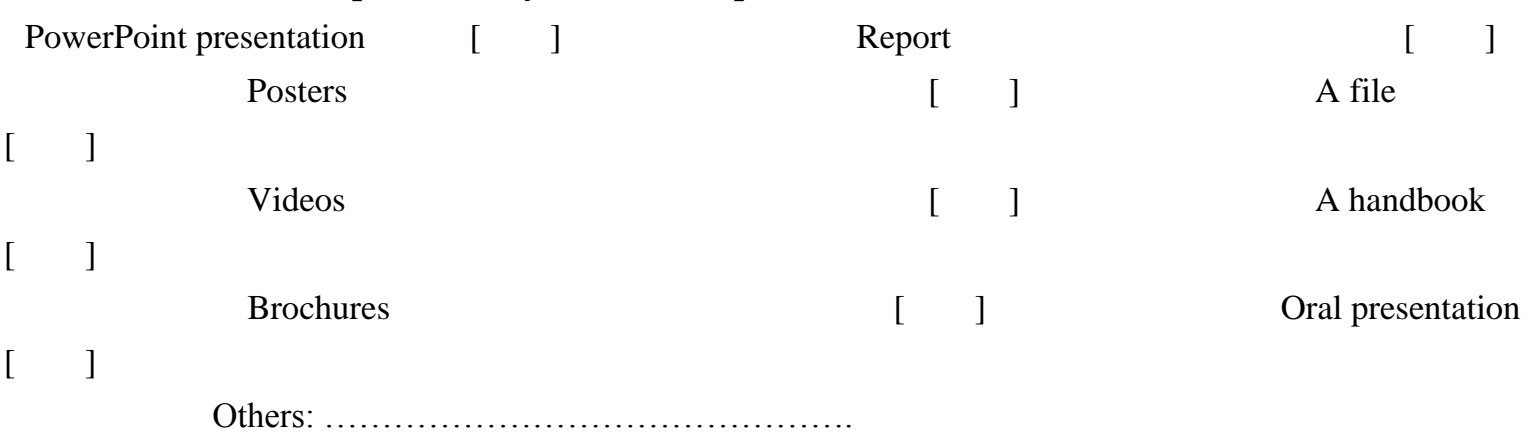

12. How do you evaluate your students' project work?

13. Does project work suit all the students' levels?

$\begin{array}{lll}\text { Yes [ ] No [ ] } & \text { No }\end{array}$

Any additional comments are more than welcome

Thank you for your contribution

\section{Students' attitudes}

These questions aim at making research on students' opinions about project work and its role in improving their autonomous learning. All the information provided by the students will be used for research purposes only.

Please answer the questions carefully. Your contribution will be totally anonymous. Thank you in advance for your contribution and for the time you will devote to answering these questions.

\section{Very important: Do not write your name.}

Please put a Tick $\checkmark$ in front of your answer.
1. Are you? Male [ ]
Female $[\quad]$
2. Where do you teach? 
Please answer the following questions.

1. Does your teacher assign project work for you?

2. If yes, do you feel any progress after producing and presenting the project?

3. What are the skills you think you develop/have developed when working on a project?

4. Do you like working in groups or individually?

5. Is your school provided with the necessary equipment to conduct project work?

6. Do you like projects related to the themes of the textbooks? Justify in any case?

7. What is the best project theme that you can work on?

8. What kind of project work presentation do you like? (oral, written, video, recording...)

9. Do you think it's a good idea to work on projects while studying?

10. Do projects help you develop your language skills? 


\section{Do you like group work?}

\section{What benefits do you gain from working on projects?}

Thank you for your contribution

\section{Copyrights}

Copyright for this article is retained by the author(s), with first publication rights granted to the journal.

This is an open-access article distributed under the terms and conditions of the Creative Commons Attribution license which permits unrestricted use, distribution, and reproduction in any medium, provided the original work is properly cited. 